\title{
Determination of potential glacial refugia and possible migration routes of Campylocentrum (Vandeae, Orchidaceae) species through the Darién Gap
}

\author{
Marta Kolanowska* \\ Department of Plant Taxonomy and Nature Conservation, University of Gdańsk, Wita Stwosza 59, 80-308 Gdańsk-Oliwa, Poland
}

\begin{abstract}
The possible glacial refugia of four Campylocentrum species reported from the Darién Gap are estimated based on the ecological niche modeling. The potential migration routes of the studied species are presented. The current ranges of all species designated based on the available floristic data are compared with their potential habitats distribution.
\end{abstract}

Keywords: Campylocentrum; Darién Gap; ENM; migration; glacial refugia

\section{Introduction}

The Darién Gap (Spanish Tapón del Darién, Fig. 1) is an area of swampland and tropical forest separating Panamian province of Darién from Colombia. The Isthmus is about $50 \mathrm{~km}$ wide, from the Carribean Sea to the North Pacific Ocean, and $84 \mathrm{~km}$ long from Yarviza (Panama) to Lomas Aisiadas (Colombia). Darién is one of the least known and most diverse regions of the World. The Panamian part of the Isthmus is covered with the rainforest, while the Colombian side is dominated by the flat marshland created in the delta of the Atrato River. In terms of floristic diversity Darién Gap is one of the least recognized region of the World, partially due to the lack of the roads in this area, which makes the field studies difficult to conduct. In fact, this is the only missing part of the Pan-American Highway, which crosses through the entirety of North, Central, and South America [1].

Undoubtedly, apart from the insufficient herbarium material collected in the Darién Gap, orchids are important part of the regional flora. Unfortunately, the exact number of the species is difficult to estimate. While Williams et al. [2] provided information only about 14 orchids occurring in the province of Darién and Cárdenas-López [3] listed 33 species found in the Colombian part of the Isthmus, the preliminary research conducted in the herbaria $\mathrm{MO}$ and AMES resulted in a list of over 250 species belonging to 11 tribes occurring in the Darién Gap.

One of the most interesting orchids are plants classified under the tribe Vandeae, which is best represented in the

\footnotetext{
*Email: martakolanowska@wp.pl
}

Handling Editor: Beata Zagórska-Marek
Paleotropics. Within this group, only the species of the subtribe Angraecinae are found also in Neotropics. Those New World plants belong to one of three genera: Campylocentrum Benth., Dendrophylax Rchb.f. or Harrisella Fawc. \& Rendle.

Proposed in 1881 [4] the genus Campylocentrum is the only representative of the tribe Vandeae in Central America. Species constituting the genus are epiphytic, monopodial, either leafy or leafless plants producing lateral inflorescence with non-resupinate, usually inconspicuous flowers. The variously 3-lobed or entire lip is always elongated into a prominent spur [5]. The geographical range of the genus extends from Florida through Mexico to Brazil. About 60 species have been described so far, just four of them have been reported from the Darién Gap: C. brenesii Schltr., C. micranthum (Lindl.) Rolfe, C. panamense Ames and C. tyrridion Garay \& Dunst. [6-8].

So far no research about the migration of Orchidaceae through the Isthmus was conducted. In this paper the maximum entropy method was applied to determine localization of potential refugia during last glacial maximum (LGM, 26 500-19 000 years ago) [9] and to estimate the possible postglacial migration routes of Campylocentrum species based on the occurrence data of their populations. Additionally, the similarities between potential ranges of the studied species are discussed.

\section{Material and methods}

\section{List of localities}

A total of over 170 herbarium specimens were studied to prepare a list of localities of the studied species populations. Moreover, the information from the electronic database of the Missouri Botanical Garden (available at http://www. 


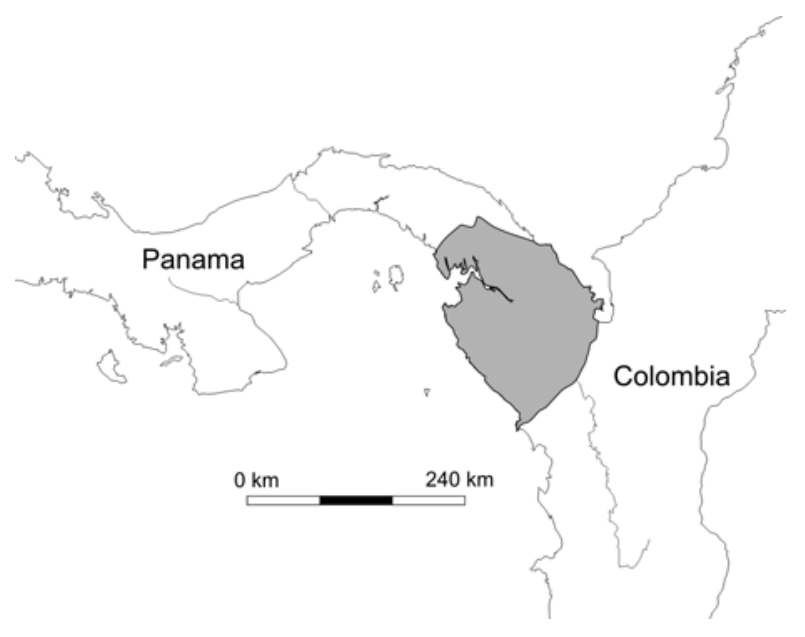

Fig. 1 Location of the Darién Gap.

tropicos.org) was used. The complete list of the examined specimens is presented in Tab. S1.

Dried herbarium specimens were examined according to the standard procedures. Every studied sheet was photographed and the data from the labels were taken. Both vegetative and generative characters of each plant were examined under a stereomicroscope. The comparison of the studied material with the designated type specimens and protologues assured the correctness of identifications. The material was examined in, or borrowed from the following institutions: AMES, AMO, COL, JAUM, K, MO, UGDA and VALLE. Moreover, the digitalized materials of AAU and RENZ were used.

Tab. 1 Variables used in the modeling.

\begin{tabular}{ll}
\hline Code & Variable \\
\hline bio1 & Annual mean temperature \\
bio2 & $\begin{array}{l}\text { Mean diurnal range = Mean of monthly (max temp - } \\
\text { min temp) }\end{array}$ \\
bio3 & $\begin{array}{l}\text { Isothermality (bio2/bio7) }(\times 100) \\
\text { bio4 }\end{array}$ \\
Temperature seasonality (standard deviation $\times 100)$ \\
bio6 & Max temperature of warmest month \\
bio7 & Min temperature of coldest month \\
bio8 & Memperature annual range (bio5 - bio6) \\
bio9 & Mean temperature of driest quarter \\
bio10 & Mean temperature of warmest quarter \\
bio11 & Mean temperature of coldest quarter \\
bio12 & Annual precipitation \\
bio13 & Precipitation of wettest month \\
bio14 & Precipitation of driest month \\
bio15 & Precipitation seasonality (coefficient of variation) \\
bio16 & Precipitation of wettest quarter \\
bio17 & Precipitation of driest quarter \\
bio18 & Precipitation of warmest quarter \\
bio19 & Precipitation of coldest quarter \\
alt & Altitude \\
\hline
\end{tabular}

\section{Maximum entropy analysis}

To estimate the potential niche for present and past, the maximum entropy analysis was made. Only the localities, which could be precisely placed on the map, were used for the analysis - a total of 183 different occurrence data, which is more than the minimum number of records required by MaxEnt to obtain trustable predictions [10].

Potential niche modeling was carried out using Maxent version 3.3.2 [11-13]. As input data 19 climatic variables in 2.5 arc minutes developed by Hijmans et al. [14], as well as the altitudinal data (Tab. 1) were used. To assess maximum specificity of the modeling, the maximum iterations was set to 10000 and convergence threshold to 0.00001 . For each run $20 \%$ of the data were used to be set aside as test points [15]. Moreover, the "random seed" option, which provided random test partition and background subset for each run, was used. The run was performed as a bootstrap with 1000 replicates, and the output was set to logistic. The analogical settings were used to estimate distribution of the suitable niches during last glacial maximum. In this modeling the data developed by the Paleoclimate Modelling Intercomparison Project Phase II [16] were applied.

\section{Results}

\section{Range - floristic data}

The maps presenting geographical ranges of the studied Campylocentrum species were prepared based on the floristic data only. While the ranges of $C$. brenesii and C. panamense seem to be restricted to the Central America, C. micranthum is widely distributed through the Neotropics. Most of C. tyrridion populations were found in Central America, but there are few records of this species from South America (Ecuador and Venezuela; Fig. 2).

\section{Ecological niche modeling}

All repeated ecological niche models for the present time received high AUC scores of 0986-0.999 (Tab. 2) that indicate great reliability of the analysis.

The results of ecological niche modeling for the present time as well as for LGM are consistent in the contributions of the analyzed climatic variables to the distribution of all studied species (Tab. 3). The crucial climatic variables deciding on the distribution of $C$. brenesii is the annual precipitation and the altitude. The altitude is also important in the modeling of the potential niches of C. tyrridion, but for this species the principal variable was the min. temperature of the coldest month. The temperature seasonality gave a significant contribution in both models made for C. micranthum and C. panamense. For the first one it was the most important variable together with the annual range of the temperature. For the second species the precipitation of the coldest quarter was essential.

The analyses indicated Cordillera de Talamanca and north part of Cordillera de San Blas as areas of suitable habitats for C. brenesii (Fig. 3a). Some additional potentially available niches are also distributed in Colombian Sierra Nevada de Santa Marta and northern Andes. In the model created 


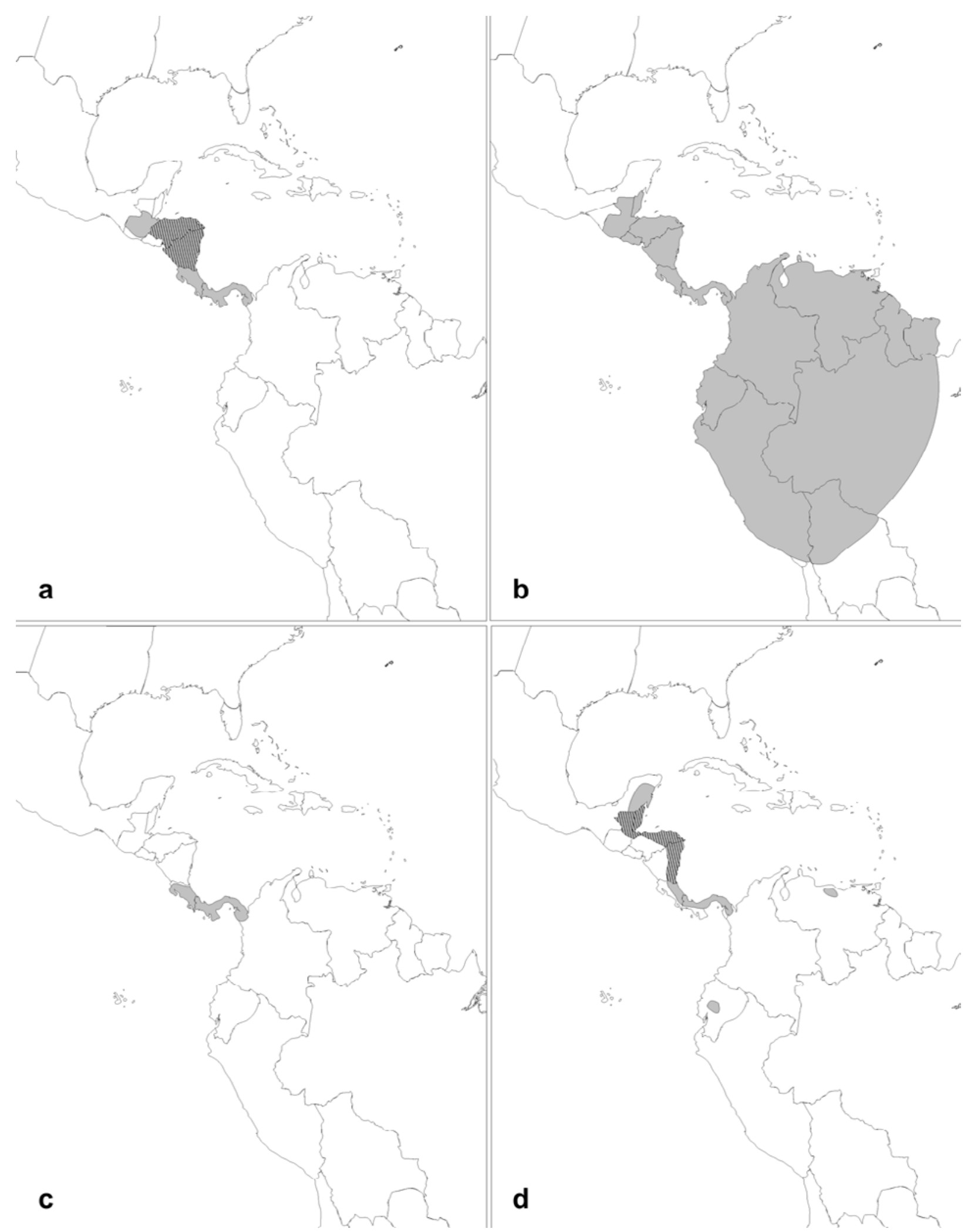

Fig. 2 Current geographical ranges of C. brenesii (a), C. micranthum (b), C. panamense (c) and C. tyrridion (d). The pattern fill was used for the unconfirmed parts of the ranges.

for C. micranthum (Fig. 3b) the most suitable habitats of this species are located along the coast of Mesoamerica as well as along the Pacific coast of Colombia, lower Orinoco and Brazilian Atlantic forests. The niches of C. panamense (Fig. 3c) are distributed along the cost of Panamian Isthmus and Brazilian Atlantic coast. Relatively extensive potential range was also indicated in the analysis of $C$. tyrridion (Fig. 3d). The niches suitable for this species are associated with the lowland areas of Neotropics, such as Atlantic coast, Orinoco lowland and Amazon region. 
Tab. 2 The AUC scores for the repeated models for different analysis per species.

\begin{tabular}{lcccc}
\hline & C. brenesii & C. micranthum & C. panamense & C.tyrridion \\
\hline Model for the present time & 0.999 & 0.993 & 0.996 & 0.987 \\
Model for LGM & 0.999 & 0.993 & 0.989 & 0.986 \\
\hline
\end{tabular}

Tab. 3 The climatic variables with the highest contribution to the potential niches distribution models.

\begin{tabular}{lllll}
\hline Species & C. brenesii & C. micranthum & C. panamense & C. tyrridion \\
\hline \multicolumn{1}{c}{ Present time } & & & & \\
\hline Var_1 (\% contribution) & Bio12 (35.8) & Bio4 (18.1) & Bio19 (23.6) & Bio6 (49.4) \\
Var_2 (\% contribution) & Alt (19.2) & Bio7 (15.8) & Bio4 (15.9) & Alt (21.8) \\
\multicolumn{1}{c}{ LGM } & & & & Bio6 (55.6) \\
Var_1 (\% contribution) & Bio12 (35.3) & Bio4 (16.9) & Bio19 (30.3) & Alt (21.0) \\
\hline Var_2 (\% contribution) & Alt (19.8) & Bio7 (15.0) & Bio4 (23.6) & \\
\hline
\end{tabular}

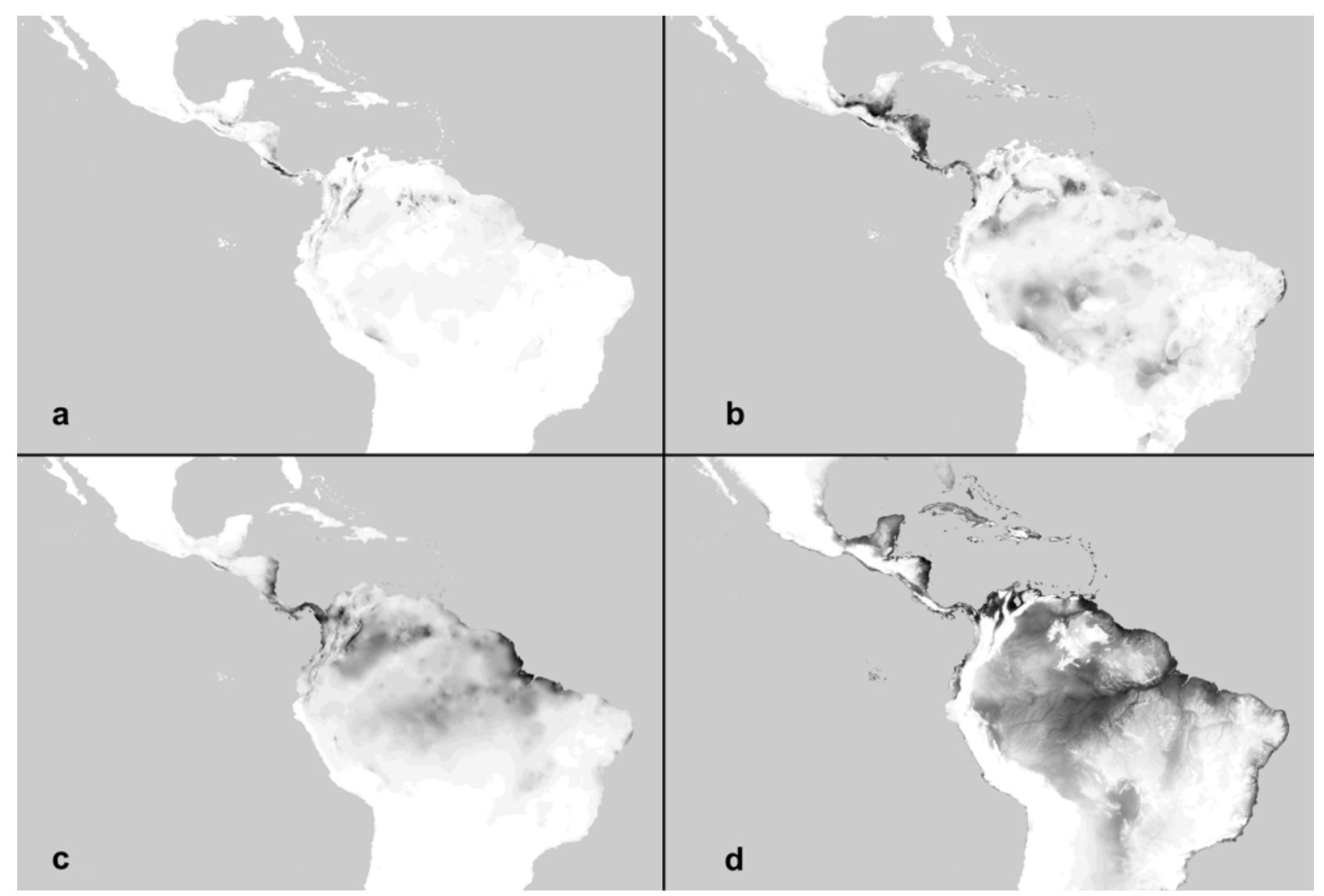

Fig. 3 Potential niche modeling for present time for C. brenesii (a), C. micranthum (b), C. panamense (c) and C. tyrridion (d).

The niche modeling for last glacial maximum shows a different distribution of suitable habitats for each studied species. For C. brenesii (Fig. 4a), the most appropriate climatic conditions included Mesoamerican Sierra Cuchumatanes and Cordillera de Talamanca as well as the northern part of the Colombian Andes. Moreover, some proper niches were located in the lower Orinoco. The most suitable niches for C. micranthum (Fig. 4b) existed in the coastal Central America as well as in the Andes from Colombia to Peru. Some appropriate habitats were also located in the eastern 


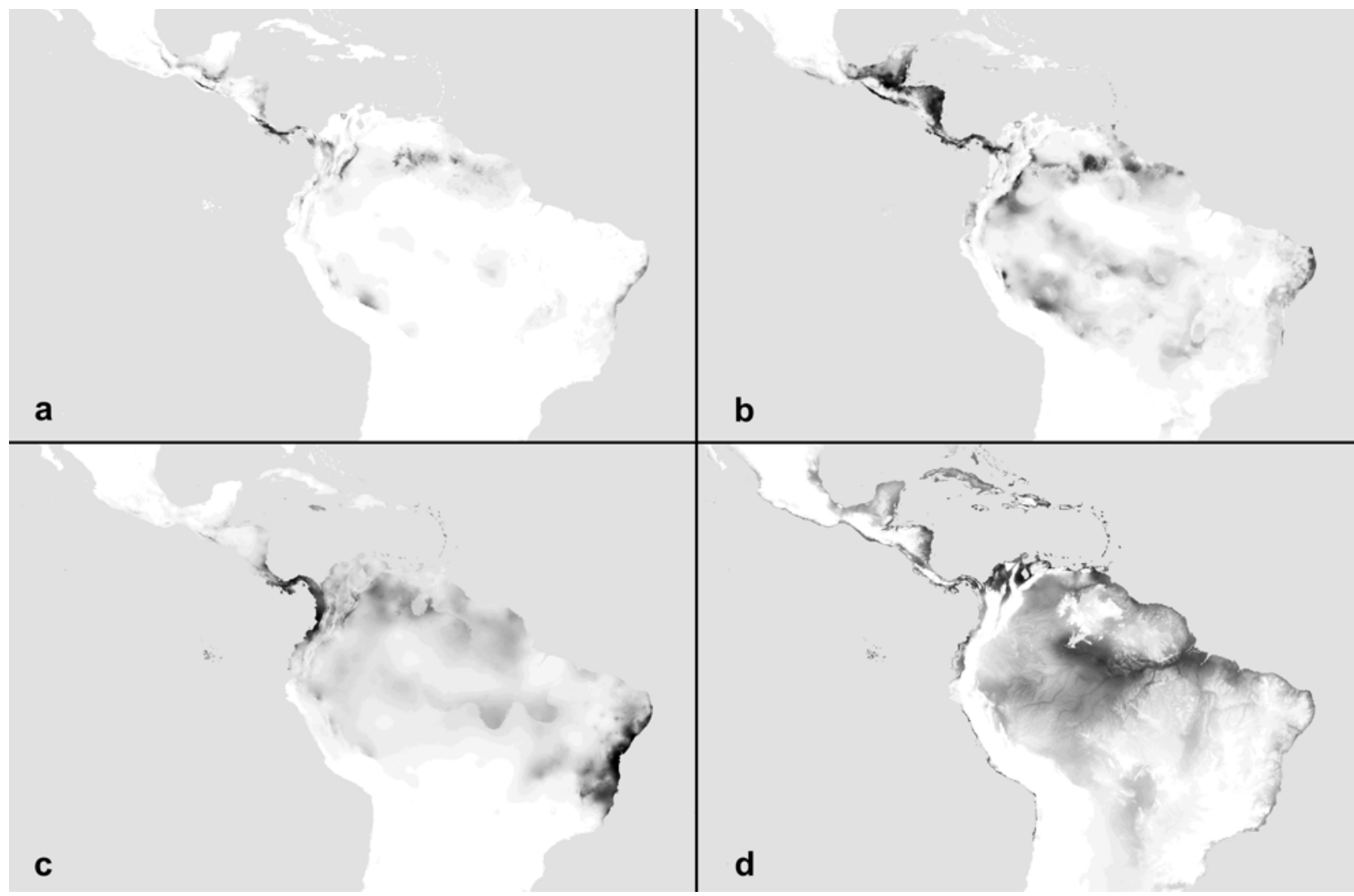

Fig. 4 Habitat fitness simulation for LGM for C. brenesii (a), C. micranthum (b), C. panamense (c) and C. tyrridion (d).

Andean slope, lower Orinoco and todays' Brazilian Atlantic forests. Along the Pacific coast of Colombia extended habitats suitable for C. panamense (Fig. 4c) and C. tyrridion (Fig. 4d) were distributed. The proper niches for the first one were also located in the Brazilian Atlantic coast and for the latter some habitats were also available in the Caribbean region.

\section{Discussion}

\section{Current species ranges}

The potential ranges estimated based on the maximum entropy analysis are significantly wider than those drawn based on the floristic data only. The latter may be underestimated due to insufficient herbarium material. While plants of Campylocentrum are rather common element of epiphytic flora of the Neotropics, especially leafless species are difficult to notice during the field works. There are also records of the sympatric occurrence of some species in Central America [8], which, due to the superficial similarity of many species, may be the reason of unrepresentative herbarium collections of Campylocentrum.

\section{Possible refugia}

Based on the results of the predictive habitat distribution modeling, the most possible distribution of the refugia was estimated. The most probable refugial areas of $C$. brenesii included Sierra Madre de Chiapas, Cordillera de Talamanca and Cordillera de San Blas.

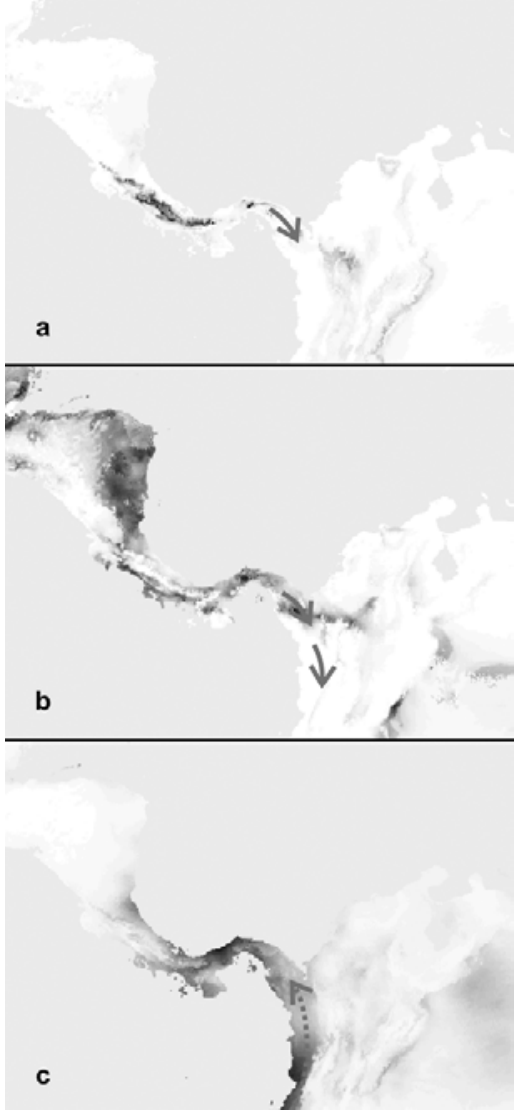

Fig. 5 Possible migration routes of C. brenesii (a), C. micranthum (b) and C. panamense (c) through the Darién Gap. 
Refugia of C. micranthum were located in Chiapas Highlands, Cordillera Chontaleña, Cordillera de Talamanca, Serranía de Tabasará, Cordillera de San Blas and Serranía del Darién in Mesoamerica, as well as in Colombian Serranía de Abibe, Serranía de San Jéronimo, Serranía de Ayapar. Region of Bocas del Toro, Panama Canal and Colombian Pacific Coast excluding Serranía del Baudó probably were refugial areas of C. panamense.

The potential refugia of $C$. tyrridion were located in the coast of Gulf of Panama, Serranía Del Sapo, coasts of Gulf of Morrosquilo, Cartagena Bay, Maracaibo Lake as well as Ecuadorian coast of Bay of Sardinas.

According to the Olsons' maps, all the areas selected here as a potential refugia corresponded during the LGM to tropical rainforest and tropical woodland [17].

\section{Estimated migration routes}

Based on the distribution of the possible refugia during the last glacial maximum and the present ranges of the studied Campylocentrum species, their migration routes through the Darién Gap were estimated and graphically presented (Fig. 5). Due to the lack of any herbarium material from Colombia and the Carribean, the migration routes of C. tyrridion could not be estimated.

\section{Acknowledgments}

This article was prepared thanks to the grants from European Commission's Research Infrastructure Action via the SYNTHESYS Project (AT-TAF-2483, GB-TAF-2445) and funding obtained from Faculty of Biology, University of Gdańsk (538-L150-B065-13). The curators and staff of the cited herbaria are thanked for their kind hospitality and assistance during visits and for making specimens available on loan.

\section{Competing interests}

No competing interests have been declared.

\section{Supplementary material}

The following supplementary material for this article is available online at http://pbsociety.org.pl/journals/index.php/asbp/rt/suppFiles/ asbp.2014.030/0:

1. Tab. S1: list of Campylocentrum specimens included in the ENM analysis.

\section{References}

1. Kanning M. Darién Gap. In: McColl RW, editor. Encyclopedia of world geography. New York, NY: Infobase Publishing; 2005. p. 234-235.

2. Williams LO, Allen PH, Dressler RL. Orchids of Panama: a facsimile reprint of "The Orchidaceae", "Flora of Panama". Saint Louis, MO: Missouri Botanical Garden; 1980. (Monographs in systematic botany; vol 4).

3. Cárdenas-López D. Inventario florístico en el Cerro del Cuchillo, Tapón del Darién Colombiano. Caldasia. 2003;25(1):101-117.

4. Bentham G. Notes on Orchidaceae. J Linn Soc Bot. 1881;18:281-361.

5. Dressler RL. Campylocentrum. In: Hammel BE, Grayum MH, Herrera C, Zamora Villalobos N, editors. Manual de plantas de Costa Rica. Saint Louis, MO: Missouri Botanical Garden; 2003. p. 38-41. (Monographs in systematic botany; vol 3).

6. Dressler RL. Field guide to the orchids of Costa Rica and Panama. New York, NY: Cornell University Press; 1993.

7. Bogarín D, Pupulin F. The genus Campylocentrum (Orchidaceae: Angraecinae) in Costa Rica: some critical questions and a few answers. In: Pridgeon AM, Suarez JP, editors. Proceedings of the second scientific conference on Andean orchids. Loja: Universidad Técnica Particular de Loja; 2009. p. 32-45.
The most probable origin of the southernmost population of $C$. brenesii found in the valley between Pirre and next most southerly peak sloping hillside was Cordillera de San Blas (Fig. 5a). There were probably several independent sources of C. micranthum, currently the widest spread through the Neotropics (Fig. 5b). In case of $C$. panamense the regression of its range is observed (Fig. 5c).

\section{Conclusions}

The maximum entropy analysis algorithms applied in the presented research seems to be a useful tool for studying the possible refugia of the plants which habitat requirements are poorly known. Moreover, the modeling of the suitable niches for LGM shows that the results of the analysis accompanied with the floristic data may indicate the possible migration routes of the species.

In both approaches, the models should be interpreted with an extreme care, taking into account the representativeness of the floristic material and factors limiting species distribution not included in the analysis, such as concurrence and the pollinator range.

8. Bogarín D, Pupulin F. The genus Campylocentrum (Orchidaceae: Angraecinae) in Costa Rica: a Revision. Harv Pap Bot. 2010;15(2):353414. http://dx.doi.org/10.3100/025.015.0216

9. Clark PU, Dyke AS, Shakun JD, Carlson AE, Clark J, Wohlfarth B, et al. The last glacial maximum. Science. 2009;325(5941):710-714. http://dx.doi.org/10.1126/science.1172873

10. Pearson RG, Raxworthy CJ, Nakamura M, Townsend Peterson A. Predicting species distributions from small numbers of occurrence records: a test case using cryptic geckos in Madagascar. J Biogeogr. 2006;34(1):102-117. http://dx.doi. org/10.1111/j.1365-2699.2006.01594.x

11. Elith J, Phillips SJ, Hastie T, Dudík M, Chee YE, Yates CJ. A statistical explanation of MaxEnt for ecologists: Statistical explanation of MaxEnt. Divers Distrib. 2011;17(1):43-57. http://dx.doi. org/10.1111/j.1472-4642.2010.00725.x

12. Phillips SJ, Dudík M, Schapire RE. A maximum entropy approach to species distribution modeling. In: ICML '04: Proceedings of the twenty-first international conference on machine learning. New York, NY: ACM Press; 2004. p. 655-662. http://dx.doi. org/10.1145/1015330.1015412

13. Phillips SJ, Anderson RP, Schapire RE. Maximum entropy modeling of species geographic distributions. Ecol Model. 2006;190(3-4):231-259. http://dx.doi.org/10.1016/j.ecolmodel.2005.03.026

14. Hijmans RJ, Cameron SE, Parra JL, Jones PG, Jarvis A. Very high resolution interpolated climate surfaces for global land areas. Int $\mathrm{J}$ Clim. 2005;25(15):1965-1978. http://dx.doi.org/10.1002/joc.1276

15. Urbina-Cardona JN, Loyola RD. Applying niche-based models to predict endangered-hylid potential distributions: are neotropical protected areas effective enough. Trop Conserv Sci. 2008;1(4):417-445.

16. Braconnot P, Otto-Bliesner B, Harrison S, Joussaume S, Peterchmitt J-Y, Abe-Ouchi A, et al. Results of PMIP2 coupled simulations of the mid-holocene and last glacial maximum. Part 1: experiments and large-scale features. Clim Past. 2007;3(2):261-277. http://dx.doi. org/10.5194/cp-3-261-2007

17. Olson JS, Allison LJ, Watts JA. Carbon in live vegetation of major world ecosystems. Report DOE/NBB-0037. Washington, DC: United States Department of Energy; 1983. 